\title{
Clínica de heridas y estomas, una propuesta de enfermería especializada
}

\section{Clinic of wounds, and stomata, a proposal for specialized nursing}

\author{
María Teresa Arroyo Hernández*
}

$\mathrm{L}$ as lesiones de la integridad de la piel, las úlceras por presión (UPP) en pacientes hospitalizados representa un problema importante debido a su prevalencia, a la vez que afecta la calidad de vida del paciente, e implican consecuencias socioeconómicas para la persona, familia e instituciones de salud, ya que aumenta la morbimortalidad, su prevención y manejo competen en gran parte al profesional de enfermería.

En México, el avance tecnológico en el cuidado de las heridas tiene su despunte hasta el final de los ochenta y principios de los noventa, en forma incipiente y aislada se inicia en algunas unidades hospitalarias. La incorporación de la terapia húmeda avanzada en nuestro país cuenta con la suficiente tecnología en hidrocoloides y alginatos, después y paulatinamente se van incorporando nuevos productos para el cuidado de las heridas dentro de los que se destacan en la actualidad como los hidrocelulares, hidrofibras, hidrogeles, colagenasas, apósitos de plata, apósitos con yodo, hidrocirugía y cierre asistido al vacío, equipo electromédico para brindar un cuidado avanzado en heridas agudas y crónicas; sin embargo, son un mínimo los profesionales de la salud que cuentan con el aval académico y sustentan la práctica profesional en la educación para el cuidado, tratamiento y seguimiento para la atención de la persona con heridas y ostomías.

La Política de Estado de Salud ${ }^{\S}$ incide sobre los determinantes de la salud y adapta los servicios de atención médica a las nuevas necesidades. Promueve altos niveles de calidad, seguridad, eficacia y eficiencia. Prioriza las acciones de promoción de la salud, la prevención de enfermedades y el control de los riesgos sanitarios. Para lograr reducir el impacto que tienen las enfermedades neurológicas y las lesio- nes sobre los individuos, sus familias y la propia sociedad. La Norma Oficial Mexicana NOM-151-SSA-1996, que establece las especificaciones sanitarias (colostomía, ileostomía y drenaje).

La Norma Oficial Mexicana NOM-045-SSA2-2005, normas y procedimientos en infecciones de herida quirúrgica, neumonías y bacteriemias deberán ser objeto de atención." El Instituto Nacional de Neurología y Neurocirugía (INNN), es una institución única en su género en México y en América Latina. Especializado en las enfermedades neurológicas, neuroquirúrgicas y neuropsiquiátricas con un alto grado importante de discapacidad y repercusión socio-laboral y familiar, debido a la diversidad de los procesos musculoesqueléticos, metabólicos, endocrinos y cardiovasculares, que conllevan la presencia de las heridas crónicas de múltiples causas (quirúrgicas y úlceras por presión), además de disfunción gastrointestinal y urinaria (estomas e incontinencia), siendo un problema importante para los servicios de la salud.

Es por ello que surge la propuesta de la creación e implementación de la Clínica de Heridas y Ostomías en el Instituto, el cual ofrezca cuidado de calidad en forma integral y especializada, con la finalidad de mejorar la prevención, y tratamiento como la rehabilitación a la persona con enfermedad neurológica secundaria a complicaciones crónicodegenerativas en el manejo de las heridas y ostomías.

$\S$ http://dof.gob.mx/nota_detalle.php?codigo=5120943\&fecha=20/11/2009 revisado marzo 062014

I http://iner.salud.gob.mx/descargas/juridico-normasmexicanas/NOM-045 ..._2009.pdf. revisado 06 Marzo 2014.

* Maestra en heridas, ostomías y quemaduras. 
Dando directriz a planes y programas educativos dirigidos al personal de salud que fundamenten un sistema de consultoría, brindado por enfermeras especializadas en el área de heridas y ostomías. Así como la realización de visitas en los servicios de hospitalización.

La incidencia de los pacientes con diferentes patologías neurológicas debido al daño neurológico que se presentan tienen mayor riesgo de presentar heridas (úlceras por presión y dehiscencias de heridas quirúrgicas) como causa secundaria a su enfermedad se les realiza una ostomía para resolver diferentes problemas gastrointestinales y respiratorios, realizando (traqueostomía y gastrostomía), pacientes con lesión de neurona motora inferior, tumores que comprometan la médula espinal, y que presentan (incontinencia urinaria o disfunción de piso pélvico).

Actualmente se tiene la necesidad de contar con evidencia científica documentada acerca de las curaciones que se realizan en el Instituto Nacional de Neurología y Neurocirugía, ya que los pacientes con heridas y ostomías, necesitan ayuda en el proceso de la cicatrización y ésta se puede proporcionar con material de curación de alta tecnología, ofreciendo la terapia húmeda mediante procesos seguros e innovadores. El Instituto Nacional de Neurología y Neurocirugía cuenta con algunos apósitos para la terapia húmeda (hidrocoloides), debido a la limitación de productos es necesario contar con toda la gama de apósitos para emplearlos de acuerdo a las necesidades de cada herida, y de esta forma ayudar en el proceso de cicatrización.

También es importante resaltar, que no se cuenta con un instrumento específico para reportar la valoración, evaluación, tratamiento y seguimiento del paciente con heridas y ostomías, el cual se puede anexar al expediente clínico, para favorecer la comunicación con el personal interdisciplinario. Por tal motivo se propone a la Subdirección de Enfermería la implementación de la Clínica de Heridas y Ostomías en el Instituto, asumiendo el compromiso de brindar una atención de calidad a la persona, conformada por un equipo interdisciplinario altamente calificado y especializado en el manejo y cuidado de las heridas y ostomías. Con el fin de que la persona pueda reintegrarse a sus actividades cotidianas con una mejor calidad de vida, así disminuyendo el uso de recursos médico-quirúrgicos, de enfermería, material para curación y medicamentos, la estancia hospitalaria prolongada, como gasto público en salud.

\section{BIBLIOGRAFÍA}

1. Disponible: http://www.conamed.gob.mx/publicaciones/pdf/REVISTA_OCT-DIC

2. Disponible http://iner.salud.gob.mx/descargas/juridico-normasmexicanas/NOM-045-..._2009.pdf

3. Aburto T. (2008) Gestión clínica y administrativa en la implementación de la curación avanzada de heridas en Chile. 1er. Congreso Latinoamericano sobre Úlceras por presión y Heridas.

4. Teresa Segovia Gómez. Cómo dar vida a una Unidad de Heridas. VIII Simposio Nacional, H. Universitario Puerta de Hierro. Majadahonda.

5. www.bostonmeddevice.com

6. Hernández HA. Gestión de la calidad, Implantación de Sistemas de Calidad.

7. Correa RJM. Manejo integral del paciente ostomizados. Editorial Alfil, México 2005.

8. Advances in Wound Care. 1999; 12 (4).

9. ob cit.

10. Clinical guide the wound care. 2a. ed. Springhouse, PA: Spinghouse Corporation; 1997.

11. OSTOMY, Wound management 1996; 3 (1 y 2).

12. Gallart E, Fuentelsaz C, Vivas GI. Enfermería clínica. 2001.

13. Garnacho, Font L, Arán R. Prevención y tratamiento de úlceras por presión.

14. Doyma E, Alfaro R. Aplicación del proceso de enfermería. Guía práctica.

15. Monterrubio y col. Hospital 12 de Octubre Madrid. $2^{\circ}$ Premio Convatec 1997. Tratamiento de las úlceras por presión, US Departamento of Health and Human.

16. Bluestein D, Javaheri A. Pressure ulcers: prevention, evaluation, and management. USA. National Library of Medicine. Am Fam Physician. 200; 78 (10): 1186-1194, [Pub Med-Cross Ref].

17. Soldevilla AJJ. Escala de Norton para evaluar Ulceras por presión. Bol Inf Farmacoter Navarra. 1999; 7 (2): 9-13.

18. Carrascal GMI et al. Prevención y tratamiento de las úlceras por presión. Bol Farmacote A P Zamora (Bol). 1997; II: 1-4. 